\title{
PRÁTICA TEATRAL E TRABALHO DE GRUPO: a distribuição de funções artísticas e administrativas no contexto brasileiro de teatro de grupo, a partir de $1990{ }^{1}$
}

\author{
Samantha Agustin Cohen ${ }^{2}$.André Carreira ${ }^{3}$.
}

Resumo : O objetivo deste artigo é apresentar o projeto de pesquisa que constituirá minha futura dissertação de mestrado pelo Programa de Pós-Graduação em Teatro - UDESC. O projeto pretende investigar estruturas e distintos modos de sobrevivência de grupos teatrais brasileiros contemporâneos das regiões sudeste e sul, criados no início da década de 1990 e com uma produção teatral de relativa importância no atual contexto teatral regional e/ou nacional.

Palavras-chave: Teatro de Grupo, divisão de funções, construção de identidade.

O presente artigo tem por finalidade apresentar o projeto de pesquisa que constituirá minha futura dissertação de mestrado pelo Programa de Pós-Graduação em Teatro - UDESC. A pesquisa pretende investigar estruturas de grupos teatrais contemporâneos, criados no início dos anos 1990 e com uma produção teatral de relativa importância dentro do atual contexto teatral regional e/ou nacional. Estes grupos serão estudados como representantes de duas regiões artísticas com distintas características sociais, políticas e econômicas, delimitadas como: "centro" e "periferia". Como representantes do "centro" serão escolhidos coletivos teatrais situados no eixo Rio de Janeiro / São Paulo, região considerada o grande pólo artístico e econômico atualmente do país. E como representantes de uma das regiões brasileiras "periféricas" ao "centro" serão selecionados coletivos teatrais dos estados do sul: Paraná, Santa Catarina e Rio Grande do Sul. Por hora, foram definidos alguns dos grupos a serem analisados: "Teatro da Vertigem" da cidade de São Paulo (SP), "Falos \& Stercos" de Porto Alegre (RS) e a "Cia Carona" de Blumenau (SC).

Esta pesquisa deseja aliar estudo bibliográfico em livros, revistas, críticas, vídeos; ao estudo de campo, através de entrevistas e visitas a ensaios e apresentações dos grupos investigados.

\footnotetext{
${ }^{1}$ Projeto de Mestrado em Teatro - PPGT/UDESC.

${ }^{2}$ Aluna do Programa de Pós-Graduação, Mestrado em Teatro - PPGT/UDESC. Bolsista DS CAPES. Atriz, pesquisadora e fundadora do Grupo Teatro em Trâmite.

${ }^{3}$ Orientador do Projeto de Pesquisa. Professor Doutor do Programa de Pós-Graduação em Teatro - CEART/ UDESC.
} 
No decorrer do trabalho pretende-se mapear e analisar a organização dos grupos, a divisão de funções artísticas e administrativas, e as relações estabelecidas entre os integrantes; a fim de perceber se estas questões influenciam na formação da identidade artística dos coletivos. Outro objetivo importante deste trabalho é tentar perceber as diferenças e semelhanças dos modos de sobrevivência dos grupos teatrais atuantes no "centro" e na "periferia" do país.

Ao final deste trabalho espera-se delinear um, ou mais, perfis de coletivos teatrais brasileiros e contemporâneos a fim de possibilitar uma reflexão sobre a realidade artística do trabalho de teatro de grupo que venha servir a diretores, atores e pesquisadores acadêmicos que se interessam pela recente história e prática teatral brasileira.

\section{Tema de estudo e problemáticas}

O foco da futura pesquisa é tentar identificar as possíveis funções artísticas e de produção, e a divisão das mesmas dentro da estrutura de teatro de grupo.

Norteada por dois eixos - a prática de teatro de grupo no Brasil e a organização e estrutura de trabalho em grupo - buscarei refletir e investigar as funções artísticas e administrativas divididas e desempenhadas por integrantes de coletivos teatrais brasileiros e contemporâneos e a influência que esta exerce na criação da identidade artística dos grupos.

Com o intuito de encontrar uma resposta para a problemática apresentada acima algumas questões devem orientar o desenvolvimento deste trabalho. São elas: Qual o contexto social, político e econômico da região habitada pelos grupos; qual o percurso histórico dos coletivos analisados; quais as estruturas artísticas e administrativas dos grupos e como são divididas as tarefas entre os membros destes coletivos; no processo criativo, quais as relações e níveis estabelecidos entre diretor teatral, ator-criador e demais artistas; quais os teóricos e técnicas foram e continuam sendo referências para estes grupos; quais os campos de atuação de cada grupo - montagem de espetáculos, trabalhos comunitários, intercâmbios, curso de formação artística; que resultados estéticos podem surgir a partir das tintas organizações; e por último, a organização dos grupos influencia na criação da identidade artística e estética dos grupos?

\section{Metodologia}


O presente projeto, e a futura dissertação de mestrado, se concretizarão com o desenvolvimento de um trabalho que pretende aliar pesquisa de campo e pesquisa bibliográfica.

Como objetos de análise serão estudados a estrutura organizacional e de produção de grupos brasileiros criados no início da década de 1990, nas cidades de Rio de Janeiro, São Paulo representantes da produção do grande "centro" artístico brasileiro, e das cidades de Curitiba, Blumenau e Porto Alegre representantes de uma fatia considerável da produção teatral emergente das "periferias" artísticas do país.

Com a pesquisa de campo almeja-se coletar informações sobre as relações e práticas de trabalho em grupo, os procedimentos técnicos, as influências teóricas e as práticas pedagógicas utilizadas pelas distintas coletividades em seus processos criativos e os resultados estéticos alcançados nos espetáculos. Para tal finalidade serão realizadas entrevistas com integrantes dos coletivos selecionados, visitas a ensaios e apresentações de cada grupo, além da coleta de materiais fotográficos e vídeos pertencentes ao arquivo dos grupos.

Já com a pesquisa bibliográfica pretende-se traçar um pequeno histórico da trajetória dos grupos estudados e do contexto social, político e histórico que envolvem as práticas teatrais.

A realização deste projeto foi dividido em três blocos: a primeira etapa, já em andamento, é reservada para o estudo teórico sobre a conformação de teatro de grupo no Brasil, o contexto histórico, social e político das regiões sul e sudeste e referências históricas da relação de trabalho teatral de grupo e uma primeira escolha dos grupos a serem analisados. Este estudo teórico inicial vem sendo realizado através da leitura e consulta a diferentes fontes bibliográficas como livros, revistas, jornais, teses, sites, vídeos, imagens, etc.

A segunda etapa será destinada à organização e execução da pesquisa de campo. Momento em que serão realizadas as entrevistas com os integrantes dos grupos teatrais selecionados numa primeira etapa ${ }^{4}$, a definição final dos coletivos que serão analisados, e uma breve pesquisa histórica da formação e trajetória dos coletivos. O tempo destinado a esta etapa do projeto dependerá muito da disponibilidade e do agendamento de datas com os grupos investigados. Sem dúvida, esta é a fase mais importante para a concretização deste trabalho. As técnicas aplicadas na segunda etapa passam pelas já citadas entrevistas, visita a ensaios e apresentações, além de análise de vídeos e materiais históricos dos grupos. Com este procedimento deseja-se coletar o maior número de informações sobre os processos criativos e

\footnotetext{
${ }^{4}$ Durante a reformulação do projeto de pesquisa, pesquisadora e orientador sentiram a necessidade de fazer um primeiro levantamento, mais abrangente, de grupos teatrais com os quais serão realizadas as primeiras entrevistas. Só após esta primeira coleta de material é que serão definidos os coletivos que mais se aproximam a proposta deste estudo.
}

DAPesquisa, Florianópolis, v.2, n.4, p. 027-035, 2007. 
espetáculos das companhias estudadas. Para que seja viável a análise da produção artística dos grupos a pesquisa manterá o foco de análise no primeiro e no último processo criativo e espetáculo, de cada grupo.

A terceira etapa será destinada a organizar todo o material recolhido nos dois primeiros momentos da pesquisa (estudo teórico e de campo) e na criação do texto final da dissertação. Abaixo segue a pré-estrutura textual pensada para o projeto, divida também em três partes.

A primeira parte da dissertação pretende tratar da possível origem da prática de teatro de grupo no Brasil - Do grupo de teatro ao teatro de grupo; o momento histórico em que esta prática começou a se estruturar - O Teatro de Grupo e a pós-modernidade; e a divisão proposta pela pesquisa da produção artística "periférica" e "central"- As denominações de “centro" e "periferia", como demarcá-las?.

A segunda parte do texto tratará mais especificamente dos coletivos analisados e das principais questões da pesquisa: Nascimento - a formação dos grupos; Táticas de sobrevivência - a divisão das funções administrativas e artísticas dos coletivos; O contexto cultural e político - a localização geográfica; Demarcação de território - o espaço de trabalho ou a sede; $\mathbf{O}$ casamento - as relações de trabalho; As práticas pedagógicas - as influências teóricas, os antepassados; A obra de arte, a identidade - o processo criativo e seus resultados estéticos. Esta estrutura se repetirá em dois momentos, um em que a pesquisa trata dos grupos situados no "grande centro" e outra, em que se estudarão os grupos situados mais "à margem".

$\mathrm{Na}$ terceira e última parte da dissertação pretende-se confrontar e refletir sobre as aproximações e divergências das atuais práticas teatrais advindas tanto do "centro" como da "periferia" do país e como estas se relacionam, se é que se relacionam.

\section{Objetivos}

O objetivo geral desta pesquisa é mapear e analisar distintas estruturas e divisão de funções artísticas e administrativas de grupos teatrais contemporâneos, criados no início dos anos 1990 na região sul e sudeste do Brasil, a fim de perceber se estas questões influenciam na formação da identidade artística dos coletivos.

Outros objetivos importantes traçados pelo presente estudo são: tentar perceber as diferenças e aproximações dos modos de sobrevivência dos grupos, os processos pedagógicos adotados por estes, as técnicas e teóricos que continuam influenciando e fundamentando os processos de criação e por último, verificar a influência que a localização geográfica exerce 
sobre as práticas dos grupos. Ao final espera-se poder delinear um, ou mais, perfis de coletivos e possibilitar uma reflexão sobre a realidade artística de grupos teatrais contemporâneos que sirva a diretores, atores e pesquisadores acadêmicos que se interessam pela recente história e prática teatral brasileira.

\section{Justificativa}

O presente projeto de pesquisa e a futura dissertação de mestrado pretende desenvolver uma reflexão de cunho teórico e histórico, sobre as experiências e práticas contemporâneas de grupos teatrais brasileiros principalmente no que diz respeito à produção artística, criação de identidade e organização administrativa dos grupos. Porém, para compreender as experiências contemporâneas desenvolvidas por grupos teatrais faz-se necessário um estudo sobre o contexto e as recentes transformações históricas, sociais e econômicas das regiões pesquisadas.

A estrutura do fazer teatral dentro da história mundial esteve sempre ligada às modificações culturais e sociais características de cada época e região, como um retrato vivo da sociedade a qual pertencia. Assim, ao desenvolver um estudo na área das artes cênicas é possível conhecer um pouco mais sobre a sociedade a que esta prática pertence.

Atualmente diversas são as práticas teatrais disseminadas, principalmente no ocidente. Com o século XX inicia-se um período que costumou-se chamar de pós-moderna. Tempo de novas e importantes mudanças na estrutura da sociedade e na trajetória do fazer artístico e teatral. Na Europa começam a surgir grupos teatrais liderados por grandes diretores como: Constantin Stanislavsky, Vselvold Meyerhold, Jerzy Grotowski, Peter Brook, Eugenio Barba, Ariane Mnouchkine entre outros. Grupos teatrais baseados em processos de pesquisa e laboratórios teatrais que pretendiam desenvolver exercícios e técnicas específicos para o treinamento e trabalho do ator. Conjuntamente a todo esse movimento artístico, inicia-se uma diluição das fronteiras entre as diversas formas de expressões artísticas e o mercado econômico regido pelo capitalismo.

O pensador contemporâneo Fredric Jameson em seu artigo intitulado “¿Fin del arte o Fin de la historia?"5 discute a questão da dissolução das fronteiras e a sobreposição dos pilares economia e cultura, mercado e arte na pós-modernidade. Segundo Jameson (1999), essa diluição fronteiriça no campo teatral começou a ser sentida por volta de 1963, na Europa.

JAMESON, Fredric. “ ¿Fin del arte o Fin de la historia?”. In: "El Giro Cultural”. Buenos Aires: Manatial, 1999. 
Tendo como movimento marcante os happenings ${ }^{6}$ em detrimento dos textos densos do chamado anti-teatro.

Esse movimento de diluição de fronteiras e sobreposição da arte e do mercado parece ter sua reverberação e começar a ser sentida no Brasil a partir das últimas duas décadas dos anos XX. Época em que é possível notar também o surgimento de uma nova conformação dos grupos teatrais o chamado teatro de grupo.

O termo teatro de grupo está vinculado à idéia de teatro alternativo. Conforme Patrice Pavis (1999) ${ }^{7}$ define: teatro alternativo seria um teatro experimental, uma alternativa ao chamado "teatro comercial", um teatro independente econômica e esteticamente falando. Poderíamos dizer alternativo no sentido de uma possível saída àqueles que procuravam fugir da arte enquanto simples mercadoria(?), um possível nicho de mercado(?).

Diferente dos artistas europeus e norte-americanos que preocupados com o caráter simbólico da arte, os artistas ligados ao movimento teatral brasileiro dos anos 1960 e 1970 praticavam o chamado teatro de militância. Um teatro engajado política e ideologicamente, que protestava contra o regime ditador, vigente na época. Teatro praticado muitas vezes com poucos recursos, mas com fortes discursos e engajamento. Segundo Carreira ${ }^{8}$ a reviravolta da prática teatral no Brasil aconteceu em meados dos anos de 1980, com o início do processo de democratização do país a militância perdeu força. Era preciso encontrar outro foco para o desenvolvimento do fazer artístico.

É nesse momento que os grupos brasileiros influenciados pelo teatro europeu da época, começam um movimento de aprimoramento das bases teatrais principalmente das técnicas de atuação. A causa política ligada diretamente à vida comunitária, dá lugar à busca dos novos elementos técnicos e artísticos, ao treinamento físico do ator e a criação de novos projetos artísticos e pedagógicos. O teatro volta-se para seu interior e procura aperfeiçoar-se a partir do trabalho do ator. Da mesma forma que os happenings afastaram-se do texto dramático tradicional na Europa, agora também os grupos teatrais brasileiros primam pela construção coletiva, pela dramaturgia a partir do trabalho do ator e da experiência de grupo.

Com essa nova prática surgem os novos 'produtos' artísticos: espetáculos, workshops, oficinas, demonstração de processos, registro e publicação dos processos criativos, work in

\footnotetext{
${ }^{6}$ Happening: "Forma de atividade que não usa texto ou programa prefixado (no máximo um roteiro ou um 'modo de usar') e que propõe aquilo que ora se chama acontecimento [...], ora ação [...], procedimento, movimento, performance, ou seja, uma atividade proposta e realizada pelos artistas e participantes, utilizando o acaso, o imprevisto e o aleatório, sem vontade de imitar uma ação exterior, de contar uma história, de produzir um significado, usando tanto todas as artes e técnicas imagináveis quanto a realidade circundante. [...]”. PAVIS, Patrice. (1999: 191).

${ }^{7}$ PAVIS, Patrice. "Dicionário de teatro"; trad. J. Guinsburg e Maria Lúcia Pereira. São Paulo: Perspectiva, 1999. ${ }^{8}$ CARREIRA, André. "Teatro de grupo anos 90: um novo espaço de experimentação". Entrevista sedida ao ItaúCultural.
}

DAPesquisa, Florianópolis, v.2, n.4, p. 027-035, 2007. 
progress, vídeos, cds, camisetas, homepages e uma infinidade de mercadorias vinculadas ao trabalho do grupo e aos seus espetáculos.

Apesar de ser uma alternativa, o teatro denominado "alternativo" esteve e continua imerso no sistema moderno e pós-moderno do capitalismo. Arte e mercado parecem mesmo ter diluído suas fronteiras. Mesmo o teatro "alternativo" e "de grupo" faz parte do que já nos adaptamos a chamar de mercado artístico cultural.

Segundo Carreira e Oliveira (2003: 95), atualmente o conceito de teatro de grupo está diretamente ligado a "manifestações teatrais que se definem pelo uso do treinamento do ator, pela busca da estabilidade do elenco, por um projeto de longo prazo e pela organização de práticas pedagógicas”. Seguindo por esta linha de pensamento pretendo estudar a prática de grupos da região sul e sudeste, seu contexto social, sua estrutura de trabalho e os resultados estéticos alcançados pelas distintas formações coletivas.

Este trabalho pretende investigar com mais detalhe a relação entre os artistas dentro de estruturas de teatro de grupo, no Brasil e as diferenças e similaridades encontradas entre as experiências artísticas produzidas em diferentes regiões brasileiras.

É possível encontrar com certa facilidade registros bibliográficos sobre as práticas artísticas de grupos teatrais contemporâneos, porém desde o início desta pesquisa foi possível perceber que existe um escasso número de registros escritos elaborados pelos grupos sobre as funções relacionadas com a produção, elaboração e manutenção de projetos e do próprio grupo enquanto organização coletiva. Normalmente, os coletivos discorrem com maior frequiência sobre seus processos de criação - ensaios, preparação de ator, criação de cenografia, bases teóricas e tudo o mais relacionado ao projeto artístico. Tal abordagem possibilita, por um lado, aprofundar a pesquisa na organização e divisão de papéis artísticos e, por outro lado, dificulta a análise dos procedimentos de manutenção do coletivo. Assim, parece de fundamental importância ao andamento desta pesquisa, a realização de entrevistas com atores, diretores e demais integrantes dos grupos em discussão.

Alguns critérios foram definidos, a priori, para ajudar na escolha dos coletivos que serão analisados futuramente neste estudo - possuir mais de dez anos de existência e continuar em atividade até o presente momento e possuírem trabalhos artísticos distintos, mas com considerável relevância dentro do contexto teatral da região onde estão localizados ou mesmo a nível nacional.

Estudar grupos com uma trajetória de mais de dez anos possibilita a esta pesquisa perceber quais as táticas de sobrevivência e dificuldades enfrentadas pelos mesmos durante a construção de seu percurso e identidade artística. 
Mais do que realizar um levantamento histórico dos grupos, é objetivo deste trabalho analisar os níveis de relação estabelecidos entre os artistas e a divisão das funções artísticas e executivas dentro de cada grupo.

A futura dissertação produzida através desta pesquisa poderá ser usada como apoio de estudos teóricos e como reflexão sobre a prática artística para grupos teatrais, diretores, atores e pesquisadores acadêmicos que se interessem pela recente história e prática teatral brasileira.

Por último, há um interesse pessoal nesta pesquisa. Desejo enquanto pesquisadora e atriz estar sempre em busca de possíveis respostas para perguntas que surgem com o decorrer da minha própria prática teatral. Sendo que minha formação artística está diretamente ligada à construção de um grupo teatral, o Teatro em Trâmite, do qual sou membro e fundadora.

O Teatro em Trâmite, de Florianópolis, surgiu do encontro de alunos de Artes Cênicas e de suas práticas teatrais realizadas para disciplinas de graduação da Universidade do Estado de Santa Catarina. Hoje o grupo está com seis anos de trajetória artística e com quatro anos de regulamentação como grupo teatral. Além da pesquisa artística, constantemente nos questionamos enquanto grupo teatral, sobre qual seria a melhor estrutura e divisão de funções administrativas e artísticas dentro do coletivo.

Assim, estudar as experiências e estruturas de grupos estáveis brasileiros é também uma forma de estudar meu próprio caminho teatral.

\section{REFERÊNCIAS}

BARBA, Eugenio. A arte secreta do ator: Dicionário de Antropologia Teatral. São Paulo. Hucite: 2000.

BAUMAN, Zygmunt. Modernidade Líquida. Trad. Plínio Dentzien. - Rio de Janeiro: Jorge Zahar Ed., 2001. Janeiro: Jorge Zahar Ed., 2005. . Identidade. Trad. Carlos Alberto Medeiros. - Rio de

BROOK, Peter. O Ponto de Mudança: quarenta anos de experiências teatrais: 1946-1987. Trad. de Antônio Mercado e Elena Gaidano. Rio de Janeiro. Civilização Brasileira, 1994.

CARREIRA e OLIVEIRA, André L. A. N. e Valéria Maria de. TEATRO DE GRUPO: modelo de organização e geração de poéticas. In: O Teatro Transcende. $\mathrm{n}^{\circ}$ 12- ano 2003. Blumenau/SC.

FERNANDES, Silvia. Teatro de grupo. São Paulo: Editora Perspectiva, 2001.

FISCHER, Stela Regina. Processo colaborativo: experiências de companhias teatrais brasileiras nos anos 90. Dissertação de mestrado. Campinas, SP: [s.n.], 2003. Orientador: Renato Cohen.- Universidade Estadual de Campinas, Instituto de Artes. 
PAVIS, Patrice. Dicionário de Teatro. São Paulo. Perspectiva: 1999.

PRADO, Décio de Almeida. História Concisa do Teatro Brasileiro. São Paulo. Edusp: 1999.

TROTTA, Rosyane. Paradoxo do Teatro de grupo no Brasil. Dissertação de mestrado. ECA USP. 1998. 